\title{
Finding the Silent Message: Nurses' Experiences of Non-Verbal Communication Preceding a Suicide
}

\author{
Patrik Rytterström ${ }^{1}$, Mirja Lindeborg'2, Sari Korhonen², Tabita Sellin ${ }^{3}$ \\ ${ }^{1}$ Department of Social and Welfare Studies, Linköping University, Linköping, Sweden \\ ${ }^{2}$ Psychiatric Specialist Care, Örebro, Sweden \\ ${ }^{3}$ University Health Care Research Centre, Faculty of Medicine and Health, Örebro University, Örebro, Sweden \\ Email: *patrik.rytterstrom@liu.se
}

How to cite this paper: Rytterström, P., Lindeborg, M., Korhonen, S., \& Sellin, T. (2019). Finding the Silent Message: Nurses' Experiences of Non-Verbal Communication Preceding a Suicide. Psychology, 10, $1-18$.

https://doi.org/10.4236/psych.2019.101001

Received: November 13, 2018

Accepted: January 7, 2019

Published: January 10, 2019

Copyright $\odot 2019$ by author(s) and Scientific Research Publishing Inc. This work is licensed under the Creative Commons Attribution International License (CC BY 4.0).

http://creativecommons.org/licenses/by/4.0/

\begin{abstract}
Suicidal individuals often communicate their intention to commit suicide, but not necessarily verbally. Psychiatric nurses play a central role in the care of patients exhibiting suicidal behaviour or thoughts. Thus, the aim of this study was to explore nurses' experiences of the indirect messages about forthcoming suicide from patients' everyday life before they committed suicide. A qualitative design was used with a phenomenological hermeneutical approach. Seven nurses working in specialist psychiatric care were interviewed about their experience of the phenomenon communication about suicide. Results show how the nurses noticed changes in patients just before they committed suicide. These changes included rapid improvement, disguise of real feelings, and unreceptiveness to further treatment or encouragements. The nurses also described patients becoming aware of painful life conditions of losing hope and confidence in the future and experiencing feelings of powerlessness or an inability to influence the situation. Their last moments were characterised by a greater preoccupation with thoughts about death and finding ways to express farewells. This manifested itself in practical preparations and expressing gratitude to people, which was understood by the nurses as a way of saying goodbye. This study shows that it is possible for skilled staff to develop an understanding of a suicidal patient's internal state and to recognise the non-verbal messages of someone who later committed suicide. The knowledge of how patients prepare and act before suicide could be used to complement a structural suicide risk assessment.
\end{abstract}

\section{Keywords}

Phenomenological Hermeneutics, Preparations for Suicide, 


\section{Introduction}

Suicide is significantly associated with psychiatric illness, particularly with unipolar or bipolar depression, schizophrenia, anxiety disorder, personality disorders, and alcohol or drug misuse (Pennel, Quesada, Begue, \& Dematteis, 2015; Runeson, Haglund, Lichtenstein, \& Tidemalm, 2016; Tidemalm, Langstrom, Lichtenstein, \& Runeson, 2008). Many suicidal patients have periods of psychiatric treatment before they complete suicide (Appleby, Dennehy, Thomas, Faragher, \& Lewis, 1999; Lizardi \& Stanley, 2010; Park, Choi, Kyoung Yi, \& Hong, 2013). About 20\% - 40\% of all suicides occur during treatment or ongoing contact with inpatient or outpatient psychiatric care (Hawton, Houston, \& Shepperd, 1999; Hoyer, Licht, \& Mortensen, 2009; Hunt et al., 2010; Kapur et al., 2013; Lönnqvist, 2009), so ongoing treatment seems unfortunately not enough to prevent someone from committing suicide. Experiences from staff working close to suicidal patients might increase our knowledge about how patients with concrete suicide plans can be identified, even though they do not disclose their suicide plans with words.

\subsection{Suicidal Process and Communication}

A suicidal process precedes most suicidal behaviours, and involves a complex and dynamic interaction between the suicidal person and their surroundings. The process is influenced by risk factors such as psychiatric illness, repeated suicide attempts, crises and personality characteristics, but also by protective factors such as interpersonal relationships, and good problem solving characteristics/coping strategies (Wasserman, 2001; Wasserman, 2016a). This process of suicidal ideation, planning, or behaviour usually takes place unobserved under the surface (Beskow, 1979; Paykel, Myers, Lindentahl, \& Tanner, 1974; Pokorny, 1974). However, many suicidal individuals communicate their intention to commit suicide. The interval from first communication of suicide to the suicide, is found to vary in average between less than one month to about four years (Rimkeviciene, O’Gorman, Hawgood, \& De Leo, 2016; Runeson, Beskow, \& Waern, 1996). The suicidal communication can be either directly or indirectly. It can be expressed in a straightforward way such as verbal expression of the intention to commit suicide, or it may be more concealed and manifest in feelings such as hopelessness, making preparations for committing suicide, giving away valuable things or wishing to be alone (Wasserman, 2016b). A lack of verbal communication has sometimes been understood by staff as patients' difficulties to express themselves or as a lack of treatment compliance (Sundvall, Titelman, \& Baarnhielm, 2018). These non-verbal, indirect messages may go unnoticed. It is therefore important that nurses and other care staff are able to recognise signs of intent to commit suicide, whether verbal or otherwise, and to determine how 
far along the suicidal process a patient has come (Wasserman, 2016b). Another challenge is to ensure that a patient's thoughts or explanation of their reasons for not wanting to live are documented; such documentations are often missing from clinical records (Sundvall et al., 2018). However, most suicidal people have a closer relationship with a next of kin, with whom they are more likely to communicate suicidal thoughts or plans. This underlines the importance of good communication between care staff and the patients' next of kin, such that suicidal communication can be better identified (Sellin, Asp, Wallsten, \& Wiklund Gustin, 2016).

\subsection{Clinical Practical Guidelines in Suicide Prevention}

The importance of identifying a patient's intent and plan to commit suicide are highlighted in several clinical guidelines. In a review by Bernert, Hom and Roberts (2014), a high (70\% - 100\%) agreement between the 22 documents (i.e. 10 clinical practice guidelines and 12 resource documents) was reported, since they consistently addressed five important recommendations, which are as follows: assessment of static and dynamic suicide risk factors, degree of suicide intent and planning, evidence-based treatments (i.e. psycho-pharmacological and psychotherapy treatments), restricting access to means and postvention practice. However, a recent review (Runeson et al., 2017) concluded that most suicide risk assessment instruments demonstrate a low sensitivity $(<80 \%)$ and fail to detect more than one out of five patients who will show suicidal behaviour or commit suicide in the future. The authors conclude that assessment instruments could serve as educational support for less experienced healthcare professionals during clinical interviews. They also emphasize the importance of giving space for the patient's narrative during the clinical assessment.

Psychiatric nurses play a central role in giving space to patient narratives because they are expected to support the patient at an individual level, not only to identify suicide risk and to prevent suicide, but also to become involved in the recovery process, which includes helping the patient to build positive self-esteem and rekindling hope (Sun \& Long, 2013). This is a very difficult and demanding task that requires time for nurses to reflect (Carlen \& Bengtsson, 2007) and the ability to understand why patients want to die (Sun, Long, Boore, \& Tsao, 2006; Tzeng, Yang, Tzeng, Ma, \& Chen, 2010). The suicidal patients communicate how their suicidal thoughts cause suffering and stress emotional imbalance, and they state their urgently need to talk about their intention to commit suicide (Berglund, Astrom, \& Lindgren, 2016).

Considering the evidence presented thus far, we can conclude that clinical guidelines agree on the importance of assessing a patient's degree of intent and planning for suicide. However, how this can be done has only been briefly described and without details (Bernert et al., 2014), and guidance about if and how care staff can recognize non-verbal communication of a planned suicide is still lacking. This is an important aspect in the development of psychiatric care that 
might play a major role in preventing suicide. Furthermore, most risk assessment instruments demonstrate a low predictive value for suicide outcome (Runeson et al., 2017). It is therefore important to improve our understanding of how patients communicate their intention to commit suicide, and how this intention manifests itself in their everyday life (Todres, Galvin, \& Dahlberg, 2007). We believe that one such source of information is the experience of psychiatric nurses, who have close contact with patients. Thus, the aim of this study was to explore nurses' experiences of indirect messages of suicide intent and planning in patients' everyday life before they committed suicide.

\section{Material and Methods}

\subsection{Participants}

A total of eight mental health nurses working in psychiatry agreed to participate in the qualitative interview. However, one withdrew, resulting in a total of seven nurses aged between 39 and 60 years. They were all mental health nurses specialising in psychiatry, and had extensive experience of psychiatric care (from 9 to 40 years). Three worked in psychiatric outpatient care, and four worked in psychiatric inpatient care.

\subsection{Sampling Strategy and Procedure}

Only nurses with experiences of caring for patients who later died due to suicide were selected for interviews to enable a deeper understanding of non-verbal communication about an imminent suicide. To encourage variation in the nurses' narratives about non-verbal communication with suicidal patients with different mental illnesses, nurses working in four psychiatric outpatient units and inpatient clinics were chosen (in general psychiatry, rehabilitation, and psychosis care). These units are all part of specialist psychiatry in the public sector in Sweden, where caring for suicidal patients and conducting suicide risk assessments are standard clinical practice. The units were contacted by a letter that explained the aim and procedure of the study, and the Chief Executive Officers gave written approval for conduction of the study. Two of the researchers (SK and ML) then informed the heads of department about the study. The same person also established contact with nurses who fulfilled the inclusion criteria (i.e. nurses with experience of working closely with psychiatric patients before they committed suicide). Exclusion criteria were nurses working in addiction clinics or in child and adolescent psychiatry. This was for methodological reasons and anticipated difficulties in differentiating suicide from death resulting from substance abuse, and to distinguish between suicidal communication and parental worries, when they communicate with both children/young patients and their parents.

\subsection{Research Ethics}

According to Swedish statute book on ethical considerations (SFS, 2003), ap- 
proval from an official research ethics committee is not required for research that involves nurses reflecting on the period before a patient's suicide. No confidential data of the person who committed suicide were used, and no patients can therefore be identified in the results. Written permission to conduct and record the interviews was, however, obtained from the hospitals, the department heads, and each participating nurse. Participants were assured that all information would be treated confidentially and according to principles of research ethics in the Helsinki declaration (World Medical Association, 2018).

\subsection{Design}

This qualitative interview study followed a phenomenological-hermeneutic method, inspired by Ricoeur (1976), in which we interviewed nurses in specialist psychiatry. The purpose of this method is to uncover the meaning of learning by interpreting interviews transcribed as text. To understand a text is to understand its essence, and is a way to search for possible meanings of an individual's experience (Lindseth \& Norberg, 2004). This involves a dynamic movement between the whole and the parts of the text, between understanding and explanation. Explanation is directed towards what the text says (the parts), while understanding is directed towards grasping the meanings, what the text is talking about (the whole in relation to its parts) (Ricoeur, 1976).

\subsection{Data Collection}

The data were collected as digitally-recorded interviews. One researcher (SK) conducted all interviews so that they were carried out as uniformly as possible. To help obtain relevant information on the phenomenon of non-verbal suicidal communication as experienced by nurses, participants were asked to think of former patients they had cared for who had subsequently committed suicide. To help access the participant's experience and to explore the potential thoughts that had led a patient to consider suicide, all interviews began with the question, "Can you tell me, in retrospect, about your experience of the subtle messages you received from the patient?". Open questions were then asked on several sub-areas to obtain an insight into the informant's individual experiences. Every direct question was followed up with open-ended questions, such as "Can you give me an example?" or "Could you please tell me more about that?". The seven interviews resulted in narratives that involved 18 patients who had committed suicide. The interview took place in 2015 at the nurses' workplaces, and lasted up to 45 minutes.

\subsection{Researcher Characteristics and Reflexivity}

Three of the researchers are experienced nurses (PR, SK and ML). Two of them work in specialist psychiatry and one is a university lecturer in psychiatric nursing education. The fourth author (TS) is a researcher in clinical psychiatry. Throughout the process of interviewing and text analysis, the researchers at- 
tempted to use the technique of "bridling", whereby pre-understanding was restrained such that that the theories, preconceptions, and expectations were reflected during the research process. As recommended by Dahlberg, Dahlberg, and Nystrom (2008), openness was encouraged during interviews and when analysing texts to help identify new ways of recognising the phenomenon in question beyond the researchers' pre-understanding.

\subsection{Data Analysis}

Three of the authors (PR, ML and SK) were involved in the first and second phases of data analysis, which were conducted in accordance with the phenomenological-hermeneutic method developed by Lindseth and Norberg (2004). The analysis started with a naïve reading of the interview transcript to grasp the text as a whole. The interview text was read through several times as open-mindedly as possible, to form a naïve understanding that would guide the second phase, the structural analysis. This phase involved trying to identify and extract essential meaning from the lived experience of nurses who had encountered the prelude to a patient's suicide. The analysis of the lived experience is based on five dimensions of the nurses' lifeworld: temporality, spatiality, intersubjectivity, embodiment and emotion attunement (Todres et al., 2007). The whole interview text was divided into units of meaning and condensed into everyday language. All four researchers compared and abstracted the condensed text to create subthemes and themes. The themes were compared with the initial naïve reading to validate this understanding. The third phase involved a comprehensive understanding, which is a critical, in-depth interpretation based on the naïve understanding, the structural analyses, the researchers' pre-understanding, and the context of caring for patients suffering from mental illness with suicidal thoughts and impulses. Quotes were chosen from the interviews (identified by interview numbers) to demonstrate the findings that emerged from the data.

\section{Results}

\subsection{Naïve Understanding}

The naïve interpretation revealed that, in retrospective, nurses experienced messages from patients shortly before their suicide. It could be how nurses experienced a change with the patient. This change could be described as an improvement in mood, but this improvement was not considered to be authentic as it contrasted with the reality of the patient's life situation. Other reported changes included patients having reached their limit and the observation that they had given up on their life situation. A patient's life situation could sometimes be physically felt by nurses, whereby they recognised patients' hopelessness as pain in their own bodies. The nurses also realised afterwards, how patients' last time in their everyday life, could be understood as signs of a forthcoming suicide, for example when a patient invited a friend for a (farewell) dinner. The nurses had been initially puzzled as to why patients expressed gratitude, but after the suicide 
they understood that this was the patients' way of saying goodbye.

\subsection{Structural Analysis}

In the thematic structural analysis, the text was re-read and divided into three themes and eight subthemes (Table 1). The themes are presented separately below, with their subthemes as subheadings in italic font. Quotes are used to illustrate the nurses' lived experience of working closely with the patient, and to validate the research findings.

\subsubsection{An unreal Change in the Patient}

The nurses described how patients in everyday life silently changed in several ways just before their suicide. These changes were perceived by nurses as a sudden improvement, disguising their real feelings and being unreceptive to further treatment or encouragement.

\section{Sudden improvement}

Prior to a patient's suicide, several nurses noticed that the patient had improved, which was evident from their physical presence in the room and how they connected with other people. These improvements, the nurses noted, was unexpected and surprising. One nurse realised that she had not seen the patient in such a good condition before.

"He had improved. He was more positive and more visible on the ward. He talked more to the staff (5).

The patient became more talkative, calm and satisfied, and the staff therefore thought he was recovering from his depression.

\section{Disguising their real feelings}

Shortly before committing suicide, the nurses reported that some patients exhibited mood swings, going back and forth between happy and miserable. Some nurses felt that they could not reach the patient or interpret their mood. They described it in terms of a patient wearing a mask, and had the impression the patient was playing a game.

“This mask I was talking about. You didn't know ... I don't really think he was showing just what he felt" (3).

Table 1. Themes and subthemes from the structural analysis.

\begin{tabular}{cl}
\hline \multicolumn{1}{c}{ Themes } & \multicolumn{1}{c}{ Subthemes } \\
\hline & Sudden improvement \\
An unreal change in the patient & Disguising their real feelings \\
& Being unreceptive to further treatment or encouragement \\
& Losing hope and confidence in the future \\
$\begin{array}{c}\text { Becoming painfully aware } \\
\text { of their life conditions }\end{array}$ & Powerlessness \\
& Give up \\
Saying goodbye & Practical preparations \\
& Expressing gratitude
\end{tabular}


The nurses interpreted this behaviour as either hiding an intention to commit suicide or simply being unwilling to let anyone see how bad their psychiatric condition was.

Being unreceptive to further treatment or encouragement

Another change the nurses observed was in some patients' attitude to receiving help. Some patients went from thankfully accepting help to gradual unreceptiveness to help and encouragement. This change was seen on the ward as well as in outpatient care after discharge, when patients expressed reluctance to embark on any new therapeutic treatment. The nurses also noticed changes in the way the patient spoke about his or her family, work, or forthcoming events. These had previously been central themes in conversations, but, just before committing suicide, the patient had become silent about life outside the ward and expressed no wish to be discharged. Nurses perceived that patients were making a silent announcement that they were no longer willing to accept help.

One nurse stated:

"( When you) try to contribute to rekindling life, you could feel how it bounces back. It was not accepted. There was nothing to replenish" (7).

In retrospect, the nurses considered the silent changes that they had identified within this theme to be understandable and logical if they were taken to mean that the patient had already decided to end his or her life.

\subsubsection{Becoming Painfully Aware of Their Life Conditions}

Within this theme, the nurses described various situations in which patients became painfully aware of how their life had turned out. The nurses became so deeply involved in the patients' suffering that they sometimes experienced pain in their own bodies. The nurses experienced how the patients became aware of their difficult life conditions, and did not see any possibility of living forwards: like a word-less message that only suicide remained as an option of easing the pain. These circumstances could, for example, involve intractable psychiatric symptoms or severe pain. They could also involve the loss of important roles such as being a mother or a company leader. The nurses understood that patients felt their entire existence to be under threat, and that they had lost hope and confidence in the future, with feelings of powerlessness and an inability to influence the situation, which made them ultimately give up.

\section{Losing hope and confidence in the future}

The nurses recognised that the patients did not see a future for themselves. They understood that the patient's life conditions were so hopeless that the present was unbearable, with no relief in sight. Nurses described different situation where patients received decisive answers, for example from an authority, that affected their whole life situation, and patients gave up their hope for a better life. They described this as the shrinking of a patient's life, resulting in experiences of a hopeless situation where external issues became unimportant. Nurses also described cases in which patients themselves realised they had given up hope of finding effective medication. One nurse quoted a patient who had a 
long-term experience of medication with major side effects:

"He said... and I cannot cope living like this, you know" (7).

The nurses understood this as a silent message of losing hope and confidence in the future. According to the nurses' accounts, the patient's darkness in life was so dense and hopeless that the patient could not imagine a better future, or any future at all. This was described by one nurse as follows:

"In a sense, her whole being felt low. She was about to be discharged and go back home, but I felt she had lost confidence in the future" (2).

The nurse could feel the patient's mood and understood that the patient could not imagine returning to everyday life after inpatient psychiatric treatment.

Powerlessness

The nurses also experienced how patients came to this painful realisation that they had lost their ability to do something, or had been stripped of their autonomy. This might have involved roles that they had lost for various reasons. One nurse described how a patient had lost his role as a company leader and how this created a feeling of powerlessness:

"He... had a sense that his wings had been cut off" (7).

This awareness yielded painful feelings of disappointment, a sense of violation, and resignation in patients. The nurses described how some patients expressed extreme anger or hatred when they became aware of this powerlessness. The nurses understood this anger as a reaction of repeatedly having been deprived their action options.

Give up

Some nurses reported that, after the pain of becoming aware of their difficult life situation, patients stopped struggling to help themselves and became silent. Nurses understood this reaction as "giving up" and the surrendering of important decisions about the future to others. This surrendering contrasted with how the patients had previously acted and how the nurses shortly before the suicide perceived that the patients took a step back from everything. This was interpreted as meaning that patients believed that they had lost the battle for their life. One nurse described how the meaning of this dejection only first became obvious after the patient's suicide.

“... but then afterwards, I thought, how quiet all that fighting went" (3).

The patients did not verbally express a death wish, but the nurses interpreted the situations described in this theme as representing an increased risk of suicide.

\subsubsection{Saying Goodbye}

The nurses described how the patients' final days in life was characterised by not only an increased preoccupation with thoughts about death, but also ways of saying goodbye. These goodbyes were shown through practical preparations and expressing gratitude.

Practical preparations

Nurses identified the practical preparations that some patients made before 
committing suicide. For example, one nurse noted how a patient made arrangements for his cat to be cared for after his death, so that it would not suffer.

"... he had made plans so that the cat would not be left alone (after his death), and he gave it away" (6).

These practical preparations concern circumstances in a patient's everyday life. For the nurses, these practical arrangements were only given meaning after the patients had committed suicide. These practical preparations were rather interpreted as "life goes on". One nurse described how she thought that life should "take a rest" before the patients' suicide, but it later turned out that the patients' everyday activities were more of a preparation:

"He finished a puzzle, drank lemonade, and talked as usual... I felt I missed this totally" (7).

The preparation was hidden from the nurse because the patient continued to carry out ordinary activities as seemingly normal.

Expressing gratitude

Shortly before they committed suicide, the patients also found opportunities to express their gratitude for all the help they had received. This implied that the patient was preparing for the end by saying thanks.

"He was so grateful... grateful for all help he had received" (6).

This gratitude also involved patients saying goodbye to important people in their lives.

One patient had weekend plans with a neighbour as soon as he was discharged from the psychiatric ward, which one nurse described as follows:

"... it was a plan for the weekend. He bought food and invited the neighbour to dinner ... but before the weekend was over, the patient had taken his own life" (1).

Within this theme, different preparations patients made before bringing their life to a close were described. In retrospect, the nurses understood that patients had silently and carefully made these arrangements as a way of preparing for the end of their life.

\subsection{Comprehensive Understanding}

In retrospect, the nurses noticed that patients changed prior to their suicide. The change was unexpected in the sense that it contradicted how the nurses understood the patient's life situation. On the one hand, they understood that the patient was aware of the darkness of their life situation. The nurses interpreted what the patient said and did as signs of hopelessness, powerlessness, and giving in to their life situation. On the other hand, patients also exhibited sudden improvements. These improvements did not make sense, and the nurses suspected that patients were disguising their feelings to hide what they were actually experiencing. This change was viewed as unreal when considered in the context of the patient's pain and suffering. After the patient had committed suicide, the nurses understood that small, practical, and everyday events were non-verbal 
signs of preparations for the end. After the suicide, these preparations seemed logical to the nurses in the light of their observations of unreal changes in the patient, and in terms of the patients' painful situation.

The overall interpretation is that the nurses experienced the expression of unbearable suffering (Rehnsfeldt \& Eriksson, 2004) and unbearable existential pain that is difficult for both the suicidal patient and the nurse to describe. This unbearable suffering, often expressed without words, nevertheless touches a nurse's own life. This is not simply a metaphor; the nurses physically sensed the patient's pain, and experienced their anxiety either physically or in the feeling of a mental burden. The nurses also have the impression of those patients, unable to bear their suffering, are wearing a mask and hiding something from the people around them. This could be interpreted as the patients' suffering not only creating a distance between themselves and others, but also an alienation from their innermost being. Thus, if a patient's behaviour is contradictory, it is a sign that he/she is trying to escape and struggle with himself/herself against the unbearable pain.

This contradiction was also at the foreground when nurses were surprised to hear patients saying how grateful and relieved they were, despite the situation. After a patient had committed suicide, the nurses understood that this was a way of saying goodbye, and interpreted it as an indication that the suffering and struggle would soon be over, in a state in which there is no longer a dichotomy between life and death or hopelessness and hope.

\section{Discussion}

The present study explored nurses' experiences of indirect messages from patients shortly before they committed suicide. The analysis revealed that the nurses recognised unreal changes in the patients, along with a painful awareness about their life situation as they prepared for death. The overall interpretation is that the nurses identified signs of unbearable suffering at the point at which the patient's painful struggle would soon be over.

Our findings indicate that suicidal patients indirectly communicate their intention to commit suicide through feelings of hopelessness and a loss of confidence in the future. In some cases, this manifested itself in behavioural changes, completely without words, and in making personal preparations for the end. This is in line with previous research reporting that communication shortly before suicide can be indirect or non-verbal (Wasserman, 2016b), and that it often takes place beneath the surface and is hidden from people in the immediate vicinity (Beskow, 1979; Paykel et al., 1974; Pokorny, 1974).

One of the themes emerging from our results is that nurses noticed unreal and unexpected changes in patients, which involved sudden improvements, for example. Simon and Gutheil, (2009) discuss why sudden and unexpected improvements in recently suicidal patients cannot be trusted, since real improvements always take place through a process involving symptom relief, better sleep 
and appetite, socialisation, and adhering to treatment. Nurses also identified changes in terms of patients becoming unreceptive or unwilling to receive further treatment. Being willing to seek help and being receptive to advice or treatment has been identified as a protective factor against suicide (Wasserman, 2016a). The changes found in our study are also in line with research describing the later phase of the pre-suicidal syndrome, where there is a period of calm after the ambivalent phase is over, and a decision is made about suicide (Ringel, 1976). In hindsight, the changes in pre-suicidal patients identified by nurses in our study might therefore be understood as unreal improvements accompanied by a loss of important protecting factors that, together with a pre-suicidal calm, indicate that a decision has been made to commit suicide.

Within the theme involving painful awareness of their life conditions, the feelings of powerlessness are consistent with those reported by Sun et al. (2006), in that patients felt powerless and unable to solve their problems or influence their situations. This theme also involved the loss of important roles. Losing an important role could mean losing a sense of purpose and belonging. Along with feelings of hopelessness, this situation is considered to generate the strongest suicidal inclinations according to the interpersonal theory of suicidal behaviour (Van Orden et al., 2015). Our findings in this theme are also in line with those reported in a literature review concerning patients' loss of hope as a result of their difficulties and suffering (Berglund, Åström, \& Lindgren, 2016).

Our findings also support the connection between psychological pain and suicide. The suicide cases reported by nurses in our study could potentially be understood as being driven by a wish to escape from unbearable psychological pain; indeed, the phenomenon of mental pain or "psychache" is a significant indication of suicide risk (Shneidman, 1998; Verrocchio et al., 2016). Being aware of signs of unbearable suffering and listening and supporting the suicidal individual gives nurses a more active role in suicide risk assessment. This care-oriented approach means that the nurses can cooperate with the patient in a caring conversation so that they can articulate, share, and understand the suffering (Fredriksson \& Eriksson, 2001); furthermore, suicidal patients want healthcare personnel to recognise and acknowledge their suffering (Vatne \& Nåden, 2014). Our findings indicate the importance of exploring an inside perspective to complement suicide risk assessments based on objective criteria. This means searching for the emotions behind the façade and trying to understand the patient's internal experience of life (Todres, Galvin, \& Dahlberg, 2014). However, this is not always possible, especially when the unbearable nature of their suffering often remains unspoken. It is therefore important to reach into the patient's inner world rather than claiming to know how the patient is thinking (Todres et al., 2014). This care-oriented approach builds trust and encourages a sense of what the patient is trying to express. This approach also helps to explain how patients at risk of suicide manage to recover through relationships with other people, and how they value a sense of belonging and a shared experience of humanity (Sellin 
et al., 2016).

To summarise, in many ways, the messages from patients identified are in line with those reported by previous qualitative reviews of work on survivors of suicide attempts (Berglund et al., 2016). However, our results diverge from the literature in some respects. The nurses in our study did not identify communication involving patients requiring protection from themselves, but rather in terms of them hiding their intention to commit suicide by disguising their pain and saying that they felt better. The nurses reported that patients also stopped fighting for themselves; while survivors of suicide described in (Berglund et al., 2016) strove to redress the balance and to regain control, the patients reported in our study had stopped trying to control the situation and had seemingly given up. Our results indicate that patients had given in to the idea that life was not worth living, and that they did not consider this in terms of sadness but rather of relief, which they conveyed to the nurses by giving the impression that they had improved and were grateful. Ultimately, it seems like the patients were preparing for the end by saying a non-verbal goodbye before they committed suicide. This way of saying goodbye is in line with the steps towards suicide outlined in the model by Werbart Tornblom, Werbart and Rydelius (2015), who describe pre-suicide acts that can be interpreted in retrospect as tacit messages of farewell, rather than explicit messages of forthcoming suicide.

\section{Strengths and Limitations}

One limitation of our study design is the use of nurses' retrospective reflections after a patient's suicide, which introduces uncertainty about whether it is possible to prevent a suicide by identifying and intervening on the basis of the reported modes of non-verbal communication. This is nevertheless an important question to address in future research. However, the fact that the communication identified by nurses was related to patients who later committed suicide could strengthen the relevance of the messages by patients contemplating suicide. Additionally, all respondents were experienced nurses that cared for suicidal patients on a daily basis, which further strengthens the credibility of the results. The general structure of the findings is applicable in the context of psychiatric inpatient and outpatient care in other Western societies. A second limitation is that the study involved a relatively small number of interviews. To enrich the data, all nurses were encouraged to consider several of their former patients who had died as a result of suicide. The number of suicide cases was then documented by the interviewer. This approach resulted in comprehensive material that contained narratives about 18 patients who had committed suicide. The data were therefore considered rich and satisfying. The internal consistency of our interpretations and the theoretical reflection on suffering and the patients' everyday life ensure the trustworthiness of method used (Lindseth \& Norberg, 2004). We nevertheless do not exclude other possible interpretations. 


\section{Conclusion}

This study shows that it is possible for skilled staff to develop an understanding of a suicidal patient's internal state and to recognise the non-verbal messages of someone who later committed suicide. The messages identified in patients are largely in line with those reported by previous research on suicide. This study advances the literature in the field by emphasising the importance of identifying hidden messages in suicidal patients who have ultimately given up, who are quietly preparing for the end, and who are clearly at immediate risk of committing suicide. Another conclusion from our results is that incorporating subjective factors, as recommended by Jones (2010), is important for comprehensive assessments. This involves consideration of not only the risk factors or warning signs that are revealed verbally in a clinical interview, but also evaluating unspoken signals and implicit communication.

\section{Implications for Clinical Practice}

This study suggests that:

- Suicidal patients should be treated with a care-oriented approach that aims to alleviate patients' suffering using an inside perspective.

- More attention should be paid to the experience of staff working closely with suicidal patients because they experience, often physically and intuitively, different elements of a patient's everyday life, and this could provide important insights into the patient's suicidal process. This study could help healthcare professionals to recognise and respond to this kind of communication.

- A more care-oriented approach implies a "caring" risk assessment, which also could strengthen patient-nurse relationships.

- Developing a strong and caring relationship with a patient that is exhibiting signs of an active suicide plan requires time. It is therefore extremely important to give staff enough time and opportunity to reflect so that they can undertake this vital task, which includes identify both direct and indirect communication from suicidal patients during their daily work.

Implications for future research could focus on how the identified signs of unbearable suffering could be a valuable complement to suicidal assessments. Future research could also study individuals who have survived suicide attempts, to reconsider experiences from the perspective of the sufferer.

\section{Acknowledgements}

This paper was supported financially by Psychiatric Specialist Care, Region Örebro County. The authors would like to thank the nurses who contributed to the interviews.

\section{Conflicts of Interest}

The authors declare no conflicts of interest regarding the publication of this paper. 


\section{Authorship Statement}

The manuscript has not been published elsewhere and it has not been submitted simultaneously for publication elsewhere.

\section{Author's Contribution}

Sari Korhonen conducted all interviews. Mirja Lindeborg and Sari Korhonen completed the initial analysis and interpretation of the interviews, and also drafted the first version of the article. Patrik Rytterström and Tabita Sellin contributed to the analysis and structure of the findings and were the main authors of this article. All authors listed meet the authorship criteria according to the latest guidelines of the International Committee of Medical Journal Editors. All authors agree with the final version of the manuscript.

\section{References}

Appleby, L., Dennehy, J. A., Thomas, C. S., Faragher, E. B., \& Lewis, G. (1999). Aftercare and Clinical Characteristics of People with Mental Illness Who Commit Suicide: A Case-Control Study. The Lancet, 353, 1397-1400. https://doi.org/10.1016/S0140-6736(98)10014-4

Berglund, S., Astrom, S., \& Lindgren, B. M. (2016). Patients' Experiences after Attempted Suicide: A Literature Review. Issues in Mental Health Nursing, 37, 715-726. https://doi.org/10.1080/01612840.2016.1192706

Bernert, R. A., Hom, M. A., \& Roberts, L. W. (2014). A Review of Multidisciplinary Clinical Practice Guidelines in Suicide Prevention: Toward an Emerging Standard in Suicide Risk Assessment and Management, Training and Practice. Academic Psychiatry, 38, 585-592. https://doi.org/10.1007/s40596-014-0180-1

Beskow, J. (1979). Suicide and Mental Disorders in Swedish Men. Acta Psychiatrica Scandinavica, 1-138.

Carlen, P., \& Bengtsson, A. (2007). Suicidal Patients as Experienced by Psychiatric Nurses in Inpatient Care. International Journal of Mental Health Nursing, 16, 257-265. https://doi.org/10.1111/j.1447-0349.2007.00475.x

Dahlberg, K., Dahlberg, H., \& Nystrom, M. (2008). Reflective Lifeworld Research. Lund: Studentlitteratur.

Fredriksson, L., \& Eriksson, K. (2001). The Patient's Narrative of Suffering: A Path to Health? An Interpretative Research Synthesis on Narrative Understanding. Scandinavian Journal of Caring Sciences, 15, 3-11. https://doi.org/10.1046/j.1471-6712.2001.1510003.x

Hawton, K., Houston, K., \& Shepperd, R. (1999). Suicide in Young People: Study of 174 Cases, Aged under 25 Years, Based on Coroners' and Medical Records. The British Journal of Psychiatry, 175, 271-276. https://doi.org/10.1192/bjp.175.3.271

Hoyer, E. H., Licht, R. W., \& Mortensen, P. B. (2009). Risk Factors of Suicide in Inpatients and Recently Discharged Patients with Affective Disorders. A Case-Control Study. European Psychiatry, 24, 317-321. https://doi.org/10.1016/j.eurpsy.2008.03.011

Hunt, I. M., Windfuhr, K., Swinson, N., Shaw, J., Appleby, L., Kapur, N., \& The National Confidential Inquiry into Suicide and Homicide by People with Mental Illnes (2010). Suicide amongst Psychiatric In-Patients Who Abscond from the Ward: A National Clinical Survey. BMC Psychiatry, 10, 14. https://doi.org/10.1186/1471-244X-10-14 
Jones, R. (2010). The Development of Nurse-Led Suicide Prevention Training for Multidisciplinary Staff in a North Wales NHS Trust. Journal of Psychiatric and Mental Health Nursing, 17, 178-183. https://doi.org/10.1111/j.1365-2850.2009.01526.x

Kapur, N., Hunt, I. M., Windfuhr, K., Rodway, C., Webb, R., Rahman, M. S., Shaw, J., \& Appleby, L. (2013). Psychiatric In-Patient Care and Suicide in England, 1997 to 2008: A Longitudinal Study. Psychological Medicine, 43, 61-71.

https://doi.org/10.1017/S0033291712000864

Lindseth, A., \& Norberg, A. (2004). A Phenomenological Hermeneutical Method for Researching Lived Experience. Scandinavian Journal of Caring Sciences, 18, 145-153. https://doi.org/10.1111/j.1471-6712.2004.00258.x

Lizardi, D., \& Stanley, B. (2010). Treatment Engagement: A Neglected Aspect in the Psychiatric Care of Suicidal Patients. Psychiatric Services, 61, 1183-1191.

https://doi.org/10.1176/ps.2010.61.12.1183

Lönnqvist, J. (2009). Major Psychiatric Disorders in Suicide and Suicide Attempters. In D. Wasserman \& C. Wasserman (Eds.), Textbook of Suicidology and Suicide Prevention: A Global Perspective (pp. 275-286). New York: Oxford University Press. https://doi.org/10.1093/med/9780198570059.003.0038

Park, S., Choi, J. W., Kyoung Yi, K., \& Hong, J. P. (2013). Suicide Mortality and Risk Factors in the 12 Months after Discharge from Psychiatric Inpatient Care in Korea: 1989-2006. Psychiatry Research, 208, 145-150. https://doi.org/10.1016/j.psychres.2012.09.039

Paykel, E. S., Myers, J. J., Lindentahl, J. J., \& Tanner, J. (1974). Suicidal Feelings in the General Population: A Prevalence Study. British Journal of Psychiatry, 124, 460-469. https://doi.org/10.1192/bjp.124.5.460

Pennel, L., Quesada, J.-L., Begue, L., \& Dematteis, M. (2015). Is Suicide under the Influence of Alcohol a Deliberate Self-Harm Syndrome? An Autopsy Study of Lethality. Journal of Affective Disorders, 177, 80-85. https://doi.org/10.1016/j.jad.2015.02.006

Pokorny, A. D. (1974). A Scheme for Classifying Suicidal Behaviors. In A. T. Beck, H. L. P. Resnick, \& D. J. Lettieri (Eds.), The Prediction of Suicide (pp. 29-44). Bowie, MD: Charles Press.

Rehnsfeldt, A., \& Eriksson, K. (2004). The Progression of Suffering Implies Alleviated Suffering. Scandinavian Journal of Caring Sciences, 18, 264-272. https://doi.org/10.1111/j.1471-6712.2004.00281.x

Ricoeur, P. (1976). Interpretation Theory: Discourse and the Surplus of Meaning. Fort Worth, TX: Texas Christian University Press.

Rimkeviciene, J., O’Gorman, J., Hawgood, J., \& De Leo, D. (2016). Timelines for Difficult Times: Use of Visual Timelines in Interviewing Suicide Attempters. Qualitative Research in Psychology, 13, 231-245. https://doi.org/10.1080/14780887.2016.1170913

Ringel, E. (1976). The Presuicidal Syndrome. Suicide and Life-Threatening Behavior, 6, 131-149.

Runeson, B. S., Beskow, J., \& Waern, M. (1996). The Suicidal Process in Suicides among Young People. Acta Psychiatrica Scandinavica, 93, 35-42. https://doi.org/10.1111/j.1600-0447.1996.tb10616.x

Runeson, B., Haglund, A., Lichtenstein, P., \& Tidemalm, D. (2016). Suicide Risk after Nonfatal Self-Harm: A National Cohort Study, 2000-2008. Journal of Clinical Psychiatry, 77, 240-246. https://doi.org/10.4088/JCP.14m09453

Runeson, B., Odeberg, J., Pettersson, A., Edbom, T., Jildevik Adamsson, I., \& Waern, M. (2017). Instruments for the Assessment of Suicide Risk: A Systematic Review Evaluat- 
ing the Certainty of the Evidence. PLOS ONE, 12, e0180292.

https://doi.org/10.1371/journal.pone.0180292

Sellin, L., Asp, M., Wallsten, T., \& Wiklund Gustin, L. (2016). Reconnecting with Oneself While Struggling between Life and Death: The Phenomenon of Recovery as Experienced by Persons at Risk of Suicide. International Journal of Mental Health Nursing, 26, 200-207.

SFS (Swedish Statute Book) (2003). Law on Ethical Considerations in Research Involving Human Beings (p. 460). (In Swedish)

Shneidman, E. S. (1998). Perspective on Suicidology: Further Reflections on Suicide and Psychache. Suicide and Life-Threatening Behavior, 28, 245-250. https://doi.org/10.1521/suli.2007.37.3.245

Simon, R., \& Gutheil, T. G. (2009). Sudden Improvement among High-Risk Suicidal Patients: Should It Be Trusted? Psychiatric Services, 60, 387-389. https://doi.org/10.1176/ps.2009.60.3.387

Sun, F. K., \& Long, A. (2013). A Suicidal Recovery Theory to Guide Individuals on Their Healing and Recovering Process Following a Suicide Attempt. Journal of Advanced Nursing, 69, 2030-2040. https://doi.org/10.1111/jan.12070

Sun, F. K., Long, A., Boore, J., \& Tsao, L. I. (2006). Patients and Nurses' Perceptions of Ward Environmental Factors and Support Systems in the Care of Suicidal Patients. Journal of Clinical Nursing, 15, 83-92. https://doi.org/10.1111/j.1365-2702.2005.01232.x

Sundvall, M., Titelman, D., \& Baarnhielm, S. (2018). Challenges of Combining Perspectives. Crisis, 39, 326-334.

Tidemalm, D., Langstrom, N., Lichtenstein, P., \& Runeson, B. (2008). Risk of Suicide after Suicide Attempt According to Coexisting Psychiatric Disorder: Swedish Cohort Study with Long Term Follow-Up. BMJ, 337, a2205. https://doi.org/10.1136/bmj.a2205

Todres, L., Galvin, K. T., \& Dahlberg, K. (2014). “Caring for Insiderness”: Phenomenologically Informed Insights That Can Guide Practice. International Journal of Qualitative Studies on Health and Well-Being, 9. https://doi.org/10.3402/qhw.v9.21421

Todres, L., Galvin, K., \& Dahlberg, K. (2007). Life World-Led Healthcare: Revisiting a Humanising Philosophy That Integrates Emerging Trends. Medicine, Healthcare and Philosophy, 10, 53-63. https://doi.org/10.1007/s11019-006-9012-8

Tzeng, W. C., Yang, C. I., Tzeng, N. S., Ma, H. S., \& Chen, L. (2010). The Inner Door: Toward an Understanding of Suicidal Patients. Journal of Clinical Nursing, 19, 1396-1404. https://doi.org/10.1111/j.1365-2702.2009.03002.x

Van Orden, K. A., Wiktorsson, S., Duberstein, P., Berg, A. I., Fassberg, M. M., \& Waern, M. (2015). Reasons for Attempted Suicide in Later Life. The American Journal of Geriatric Psychiatry, 23, 536-544. https://doi.org/10.1016/j.jagp.2014.07.003

Vatne, M., \& Nåden, D. (2014). Patients' Experiences in the Aftermath of Suicidal Crises. Nursing Ethics, 21, 163-175. https://doi.org/10.1177/0969733013493218

Verrocchio, M. C., Carrozzino, D., Marchetti, D., Andreasson, K., Fulcheri, M., \& Bech, P. (2016). Mental Pain and Suicide: A Systematic Review of the Literature. Front Psychiatry, 7, 108. https://doi.org/10.3389/fpsyt.2016.00108

Wasserman, D. (2001). A Stress-Vulnerability Model and the Development of the Suicidal Process. In D. Wasserman (Ed.), Suicide (pp. 13-27). London: CRC Press. https://doi.org/10.1201/b14713-5

Wasserman, D. (2016a). Negative Life Events and Suicide. In D. Wasserman (Ed.), Suicide an Unnecessary Death (2nd ed.). New York: Oxford University Press. 
https://doi.org/10.1093/med/9780198717393.003.0014

Wasserman, D. (2016b). The Suicidal Process. In D. Wasserman (Ed.), Suicide an Unnecessary Death (2nd ed.). Oxford: Oxford University Press. https://doi.org/10.1093/med/9780198717393.003.0003

Werbart Tornblom, A., Werbart, A., \& Rydelius, P. A. (2015). Shame and Gender Differences in Paths to Youth Suicide: Parents' Perspective. Qualitative Health Research, 25, 1099-1116. https://doi.org/10.1177/1049732315578402

World Medical Association (2018). Declaration of Helsinki-Ethical Principles of Medical Research Involving Human Subjects. 